\section{Integrative Medicine \\ International}

Integr Med Int 2014;1:211-222

\title{
The Effect of Riding as an Alternative Treatment for Children with Cerebral Palsy: A Systematic Review and Meta-Analysis
}

\author{
Guoqin Wang $^{a}$ Ruiqin Mac ${ }^{c}$ Guangwei Qiao $^{d}$ Koji Wadab \\ Yoshiharu Aizawa $^{b}$ Toshihiko Satoh ${ }^{a}$ \\ ${ }^{a}$ Kitasato Clinical Research Center and ${ }^{b}$ Department of Public Health, Kitasato University \\ School of Medicine, Sagamihara, Japan; 'The People's Hospital of Dengkou Prefecture, \\ Bayannaoer, and ${ }^{\mathrm{d}}$ General Hospital of Ningxia Medical University, Yinchuan, PR China
}

\section{Key Words}

Cerebral palsy · Equine-assisted therapy · Gross motor function · Hippotherapy ·

Hippotherapy simulator, meta-analysis · Posture · Powered saddle · Systematic review .

Therapeutic horseback riding

\section{Abstract}

Background and Objectives: There is a substantial body of evidence assessing the effects of equine-assisted therapy on physiological and psychological aspects of individuals with disabilities. This study aimed to evaluate the physiological benefits of this alternative therapy for children with cerebral palsy (CP) by means of a systematic review and meta-analysis. Methods: This systematic review included all randomized and nonrandomized clinical trials of hippotherapy (HT), therapeutic horse riding (THR), and artificial saddle (AS) for the treatment of children with CP by a systematic search in Medline, Embase, Cochrane Library, and other databases up to November 2012. Articles were assessed for inclusion eligibility and quality by two independent reviewers. Any discordant case was re-reviewed and consensus was obtained after sufficient discussion. A random effects model of meta-analysis was applied to provide summary statistics for each outcome. Results: Seven randomized controlled trials (RCTs), 4 non-RCTs, and 7 self-controlled studies were included for quality assessment. Ten studies assessed the effect of HT, 5 evaluated THR, and 3 evaluated AS. The sample size differed from 3 to 72, and the quality ranged from low to moderate. Six studies were included in the meta-analysis, and there was a significant improvement in the 66-item Gross Motor Function Measure (GMFM-66), the GMFM-66/88 total score, and the dimension E of the GMFM. Although the asymmetry score tended to be reduced, it failed to reach statistical significance. Conclusions: HT, THR, and AS seem to improve the total score of the gross motor 
function via improvement of the walking, running, and jumping dimension. However, they are not likely to be of benefit to the symmetry of postural muscle activity. Studies included in this review lack high-quality RCTs with a sufficient number of subjects, which thus warrants further evaluations of these modalities using large-scale well-designed RCTs.

(c) 2015 S. Karger AG, Base

\section{Introduction}

Cerebral palsy (CP) is a nonprogressive disorder due to insults to the developing fetal or infant brain in single or multiple locations that control movement and posture [1]. A therapeutic horseback riding program can be defined as a riding program with the primary objective of rehabilitation rather than solely recreation or the teaching of riding skills. Although the anatomic lesion is static, sensory and motor impairments combined with postural asymmetries often lead to severe disability and account for progressive dysfunction $[2,3]$. Physical therapy utilizing the movement of a horse [4], such as hippotherapy (HT), developmental equine-assisted therapy, and therapeutic horseback riding (THR), has been used for decades in order to improve posture [5], balance [6], and the overall function of children with CP [7]. Although there are some discrepancies in the definition of HT and THR [8], according to the description in the available articles, physical therapy using a horse as an alternative therapy for children with CP can generally be defined as a riding program with the primary objective of rehabilitation rather than solely recreation or the teaching of riding skills $[9,10]$.

A substantial body of evidence applying a qualitative or quantitative study design has assessed the effects of HT/THR on physiological and psychological aspects of individuals with disabilities [11, 12]. Recently, the effects of an artificial saddle (AS) has been increasingly investigated, which serves as a HT simulator and simulates the rhythmic, multidimensional movement of a walking horse [13-15]. This study aimed to evaluate the benefits of HT/THR as well as AS for children with CP by means of a systematic review and meta-analysis.

\section{Methods}

This study was conducted and reported in accordance with the QUOROM and PRISMA guidelines $[16,17]$.

\section{Information Sources and Searching}

We used the following sources for the identification of relevant articles: Medline via PubMed (1966 to November 2012), Embase via Ovid (1974 to November 2012), and the Cochrane database of systematic reviews via Ovid (2005 to November 2012). MeSH (medical subject headings) terms or key words such as 'cerebral palsy', 'equine-assisted therap*', 'hippotherap*', 'horseback riding therap*', 'pony riding', and 'saddle' were included in the search. Hand searching of the references section of each included article was also performed for the identification of other studies.

\section{Study Selection and Eligibility Criteria}

All studies identified through databases and hand searching were first screened for eligibility by looking at titles and abstracts after having been checked for duplicates. The full text of an article was eligible for inclusion if it (1) included children with CP, (2) assessed the effects of HT, THR or AS, (3) measured the gross motor function or other physical outcomes 
of each participant, and (4) had a quantitative study design. We excluded studies from this review if the outcomes of interest were not objectively evaluated, if the study was not an original study or if studies had been published in languages other than English, Japanese or Chinese.

\section{Assessment of Risk of Bias and Data Extraction}

Methodological quality was assessed independently by two review authors (G.W., R.M.). Disagreements were reviewed and discussed until a consensus was obtained, or a third review author (T.S.) was consulted to reach a final decision. The Cochrane Risk of Bias tool was used for quality assessment and a graph displaying the risk of bias was obtained including the following dimensions: (1) random sequence generation (selection bias); (2) allocation concealment (selection bias); (3) blinding of participants and personnel (performance bias); (4) blinding of outcome assessment (detection bias); (5) incomplete outcome data (attrition bias); (6) selective reporting (reporting bias), and (7) other bias. Assessment resulted in three categories: low risk, unclear risk, and high risk. No quality score was calculated for this assessment.

The following pieces of information were extracted from each study: first author, publication year, subject characteristics, type and duration of the intervention and control treatment, outcomes and measurements of each study, study design, statistical method for comparison, results, and conclusions.

\section{Summary of Measurements}

Measures of physical outcomes of CP patients included symmetry of postural muscle activity and gross motor function. Symmetry of postural muscle activity refers to that assessed using remote telemetered surface electromyography [18]. The activity of the skeletal muscle is measured through overlying skin electrodes. The strength and variations of the signals picked up via the electrodes are recorded in microvolts. For data synthesis within this review, an asymmetry score was applied to reflect the unbalanced activities of left- and right-side muscle groups, which was defined as absolute difference in mean microvolt readings between the left and the right side. The gross motor skills of the subjects were assessed using the Gross Motor Function Measure (GMFM). The GMFM score includes a GMFM-88 and GMFM-66 version, where GMFM-88 consists of 88 items and GMFM- 66 of 66 items. Both scales were organized into the following 5 dimensions reflecting 5 different motor skills: (A) lying and rolling, (B) sitting, (C) crawling and kneeling, (D) standing, and (E) walking, running and jumping [19]. A 4-point Likert scale assessment was used for each item (1 = does not initiate, $1=$ initiates, 2 = partially completes, and $3=$ completes). The total dimension score refers to the sum of scores for each item within a certain dimension divided by a constant as indicated in the user's manual [19]; the total score refers to the average of the total dimension scores. The total dimension score or the total score was used for data synthesis within this review. Other possible measures used included the Peabody Developmental Motor Scale designed for children from birth through 83 months, the Ashworth Scale developed for measuring muscle tone, the Sitting Assessment Scale for evaluating sitting balance, the postural scale using videotaped motion analysis for assessing postural control, temporospatial parameters such as stride length, cadence and walking speed, and pelvic and hip kinematics such as pelvic anterior tilt, pelvic range of motion, and range of hip flexion/extension were used to evaluate gait function.

\section{Synthesis of Results}

For each of the outcomes, the mean before-and-after changes of the HT/THR/AS group and the control group were used to obtain an overall effect size. This study did not evaluate 
Fig. 1. Flow chart of the study se-

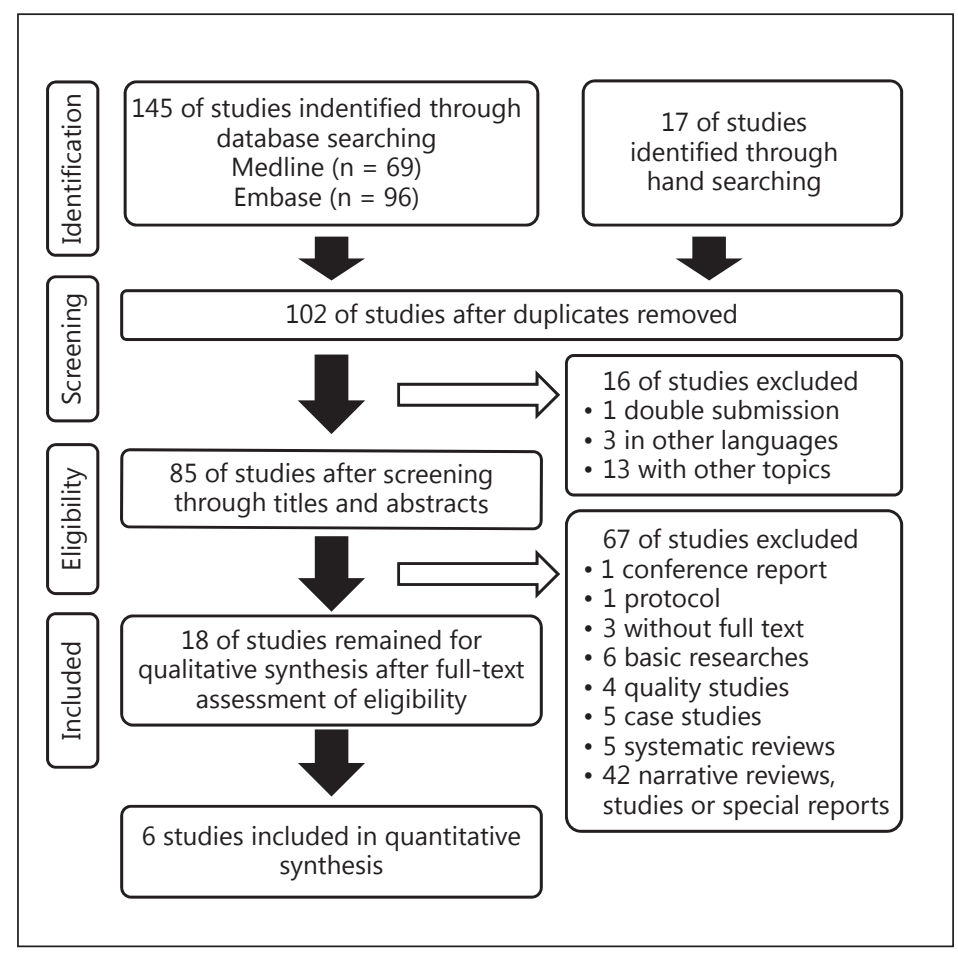
lection.

the carryover effect of HT/THR/AS, which was measured sometime after the intervention. A meta-analysis was performed using Review Manager (RevMan) version 5 (Cochrane Collaboration, Oxford, UK). A fixed effects model was first applied for each outcome, and the $I^{2}$ statistic was adopted for assessing heterogeneity; in case there is high heterogeneity $\left(I^{2}>40 \%\right)$, a random effects model was planned to be applied instead. A funnel plot was used to explore any publication bias if applicable, and sensitivity analyses within studies with a randomized controlled trial (RCT) design or studies on AS were planned as appropriate.

\section{Results}

\section{Study Selection}

The flow chart of the study identification and selection is depicted in figure 1. A total of 145 articles identified from databases or hand searching were included. One hundred and two articles were included for the assessment of eligibility after having been checked for duplicates. Sixteen articles were excluded after title and abstract screening. Full-text evaluation resulted in 18 studies for quality assessment, and 6 studies for meta-analysis. The reasons for exclusion are presented in figure 1.

\section{Study Characteristics}

Study characteristics are summarized in table 1 . The number of participants of the 18 studies eligible for quality assessment varied from 3 to 72; all studies focused on children with CP. The participants consisted of female or male children aged 2-18 years. There are 10 studies assessing the effect of HT, 5 studies evaluating THR, and 3 studies evaluating AS. The periods of these interventions differed from a single 8-min session of riding to 60 min once a week for 26 weeks. Seven studies were self-controlled studies [5, 10, 20-24], 4 were non-RCTs 
Wang et al.: The Effect of Riding as an Alternative Treatment for Children with Cerebral

Palsy: A Systematic Review and Meta-Analysis

Table 1. Characteristics of studies included for quality assessments

\begin{tabular}{|c|c|c|c|c|c|c|c|c|}
\hline $\begin{array}{l}\text { First author, } \\
\text { year }\end{array}$ & $\begin{array}{l}\text { Study } \\
\text { design }\end{array}$ & $\begin{array}{l}\text { Patient } \\
\text { number } \\
(\mathrm{I} / \mathrm{C})\end{array}$ & $\begin{array}{l}\text { Age, } \\
\text { years }\end{array}$ & $\begin{array}{l}\text { Inter } \\
\text { vention }\end{array}$ & Duration & Frequency & Control & Outcomes \\
\hline $\begin{array}{l}\text { Benda [29], } \\
2003\end{array}$ & $\begin{array}{l}\text { RCT } \\
\text { (ID) }\end{array}$ & $7 / 8$ & $4-12$ & $\mathrm{HT}$ & Once & $8 \mathrm{~min}$ & $\begin{array}{l}\text { Waiting list } \\
\text { with barrel } \\
\text { sitting }\end{array}$ & Asymmetry score \\
\hline $\begin{array}{l}\text { Bertoti [5], } \\
1988\end{array}$ & Self-controlled & $11 / 0$ & $2-9$ & THR & 10 weeks & $\begin{array}{l}60 \mathrm{~min} / \text { day, } \\
\text { twice/week }\end{array}$ & NA & $\begin{array}{l}\text { Interval composite } \\
\text { score, function ability }\end{array}$ \\
\hline $\begin{array}{l}\text { Casady [20], } \\
2004\end{array}$ & Self-controlled & $10 / 0$ & $3-6$ & HT & 10 weeks & $\begin{array}{l}20-30 \mathrm{~min} / \text { day, } \\
\text { once/week }\end{array}$ & NA & GMFM-88, PEDI \\
\hline $\begin{array}{l}\text { Cherng [25], } \\
2004\end{array}$ & Non-RCT & $9 / 5$ & $3-12$ & THR & 16 weeks & $\begin{array}{l}40 \mathrm{~min} / \mathrm{day}, \\
\text { twice/week }\end{array}$ & $\begin{array}{l}\text { Conventional } \\
\text { physiotherapy }\end{array}$ & $\begin{array}{l}\text { GMFM, hip adductor } \\
\text { muscle tone } \\
\text { (Ashworth scale) }\end{array}$ \\
\hline $\begin{array}{l}\text { Davis [30], } \\
2009\end{array}$ & $\begin{array}{l}\text { Stratified } \\
\text { RCT }\end{array}$ & $50 / 49$ & $4-12$ & THR & 10 weeks & $\begin{array}{l}30-40 \mathrm{~min} / \\
\text { day, once/week }\end{array}$ & Waiting list & $\begin{array}{l}\text { GMFM-66, quality of } \\
\text { life }\end{array}$ \\
\hline $\begin{array}{l}\text { Hamill [10], } \\
2007\end{array}$ & Self-controlled & $3 / 0$ & $2-4$ & HT & 10 weeks & $\begin{array}{l}50 \mathrm{~min} / \mathrm{day}, \\
\text { once/week }\end{array}$ & NA & $\begin{array}{l}\text { GMFM-88, Sitting } \\
\text { Assessment Scale }\end{array}$ \\
\hline $\begin{array}{l}\text { Herrero [31], } \\
2010\end{array}$ & $\begin{array}{l}\text { Stratified } \\
\text { RCT }\end{array}$ & $19 / 19$ & $4-18$ & HS & 10 weeks & $\begin{array}{l}15 \mathrm{~min} / \mathrm{day}, \\
\text { once/week }\end{array}$ & $\begin{array}{l}\text { Simulator } \\
\text { switched off, } \\
\text { waiting list }\end{array}$ & $\begin{array}{l}\text { GMFM-66 (B), Sitting } \\
\text { Assessment Scale }\end{array}$ \\
\hline $\begin{array}{l}\text { Kwon [26], } \\
2011\end{array}$ & Non-RCT & $16 / 16$ & $4-10$ & HT & 8 weeks & $\begin{array}{l}30 \mathrm{~min} / \mathrm{day}, \\
\text { twice/week }\end{array}$ & $\begin{array}{l}\text { Conventional } \\
\text { physiotherapy }\end{array}$ & $\begin{array}{l}\text { GMFM-88, GMFM- } 66 \\
\text { temporospatial, pelvic } \\
\text { and hip }\end{array}$ \\
\hline $\begin{array}{l}\text { MacKinnon } \\
{[6], 1995}\end{array}$ & $\begin{array}{l}\text { Stratified } \\
\text { RCT }\end{array}$ & $10 / 19$ & $4-12$ & THR & 26 weeks & $\begin{array}{l}60 \mathrm{~min} / \mathrm{day}, \\
\text { once/week }\end{array}$ & Waiting list & $\begin{array}{l}\text { GMFM, Bertoti Scale, } \\
\text { Bruininks-Oseretsky } \\
\text { Test, Peabody } \\
\text { Developmental Motor } \\
\text { Scale }\end{array}$ \\
\hline $\begin{array}{l}\text { McGibbon } \\
{[21], 1998}\end{array}$ & Self-controlled & $5 / 0$ & $9-11$ & HT & 8 weeks & $\begin{array}{l}30 \mathrm{~min} / \mathrm{day} \\
\text { twice/week }\end{array}$ & NA & $\begin{array}{l}\text { GMFM-E, energy } \\
\text { expenditure index, } \\
\text { stride, candence }\end{array}$ \\
\hline $\begin{array}{l}\text { McGee [22], } \\
2009\end{array}$ & $\begin{array}{l}\text { Self-controlled } \\
\text { (ID) }\end{array}$ & $9 / 0$ & $7-18$ & HT & Once & $35-40 \mathrm{~min}$ & NA & Gait parameters \\
\hline $\begin{array}{l}\text { McGibbon } \\
\text { [23], } 2009 \\
\text { (phase I) }\end{array}$ & RCT & $25 / 22$ & $4-16$ & HT & Once & $10 \mathrm{~min}$ & $\begin{array}{l}\text { Waiting list } \\
\text { with barrel } \\
\text { sitting }\end{array}$ & $\begin{array}{l}\text { Asymmetry score, } \\
\text { GMFCS level, } \\
\text { GMFM-66 }\end{array}$ \\
\hline $\begin{array}{l}\text { McGibbon } \\
\text { [23], } 2009 \\
\text { (phase II) }\end{array}$ & $\begin{array}{l}\text { Self-controlled } \\
\text { (ID) }\end{array}$ & $6 / 0$ & $4-16$ & HT & 12 weeks & $\begin{array}{l}30 \mathrm{~min} / \mathrm{day}, \\
\text { once/week }\end{array}$ & NA & $\begin{array}{l}\text { Asymmetry score, } \\
\text { GMFM-66, self- } \\
\text { perception }\end{array}$ \\
\hline $\begin{array}{l}\text { Quint [14], } \\
1998\end{array}$ & $\begin{array}{l}\text { Matched } \\
\text { RCT }\end{array}$ & $13 / 13$ & $9-16$ & HS & $\begin{array}{l}4 \text { weeks } \\
\text { (10 times) }\end{array}$ & $\begin{array}{l}10 \mathrm{~min} / \mathrm{day}, 2- \\
3 \mathrm{times} / \text { week }\end{array}$ & Static saddle & ROM, AP pelvic \\
\hline $\begin{array}{l}\text { Shurtleff [27], } \\
2009\end{array}$ & $\begin{array}{l}\text { Self-controlled } \\
\text { (healthy) }\end{array}$ & $\begin{array}{l}11 / 8 \\
\text { (healthy) }\end{array}$ & $5-18$ & HT & 13 weeks & $\begin{array}{l}46 \mathrm{~min} / \mathrm{day}, \\
\text { twice/week }\end{array}$ & Healthy people & $\begin{array}{l}\text { ROM, head angle, AP } \\
\text { transition }\end{array}$ \\
\hline $\begin{array}{l}\text { Shurtleff [28], } \\
2010\end{array}$ & $\begin{array}{l}\text { Self-controlled } \\
\text { (healthy) }\end{array}$ & $\begin{array}{l}6 / 6 \\
\text { (healthy) }\end{array}$ & $5-17$ & HT & 12 weeks & $\begin{array}{l}45 \mathrm{~min} / \mathrm{day}, \\
\text { twice/week }\end{array}$ & Healthy People & $\begin{array}{l}\text { ROM, MV of angles, } \\
\text { angular excursion }\end{array}$ \\
\hline $\begin{array}{l}\text { Silva e Borges } \\
{[15], 2011}\end{array}$ & RCT & $20 / 20$ & $3-12$ & HS & 6 weeks & $\begin{array}{l}40 \mathrm{~min} / \mathrm{day}, \\
\text { twice/week }\end{array}$ & $\begin{array}{l}\text { Conventional } \\
\text { physiotherapy }\end{array}$ & $\begin{array}{l}\text { Sitting posture control } \\
(\mathrm{AP}, \mathrm{ML})\end{array}$ \\
\hline $\begin{array}{l}\text { Sterba [24], } \\
2002\end{array}$ & Self-controlled & $17 / 0$ & $5-16$ & THR & 18 weeks & $\begin{array}{l}60 \mathrm{~min} / \text { day, } \\
\text { once/week }\end{array}$ & NA & GMFM-88 \\
\hline
\end{tabular}

I = Intervention; C = control; HS = hippotherapy simulators; PEDI = Pediatric Evaluation of Disability Inventory; ROM = range of motion; $\mathrm{MV}=$ movement variability; $\mathrm{AP}$ = anteroposterior; $\mathrm{ML}=$ mediolateral. 
Wang et al.: The Effect of Riding as an Alternative Treatment for Children with Cerebral Palsy: A Systematic Review and Meta-Analysis

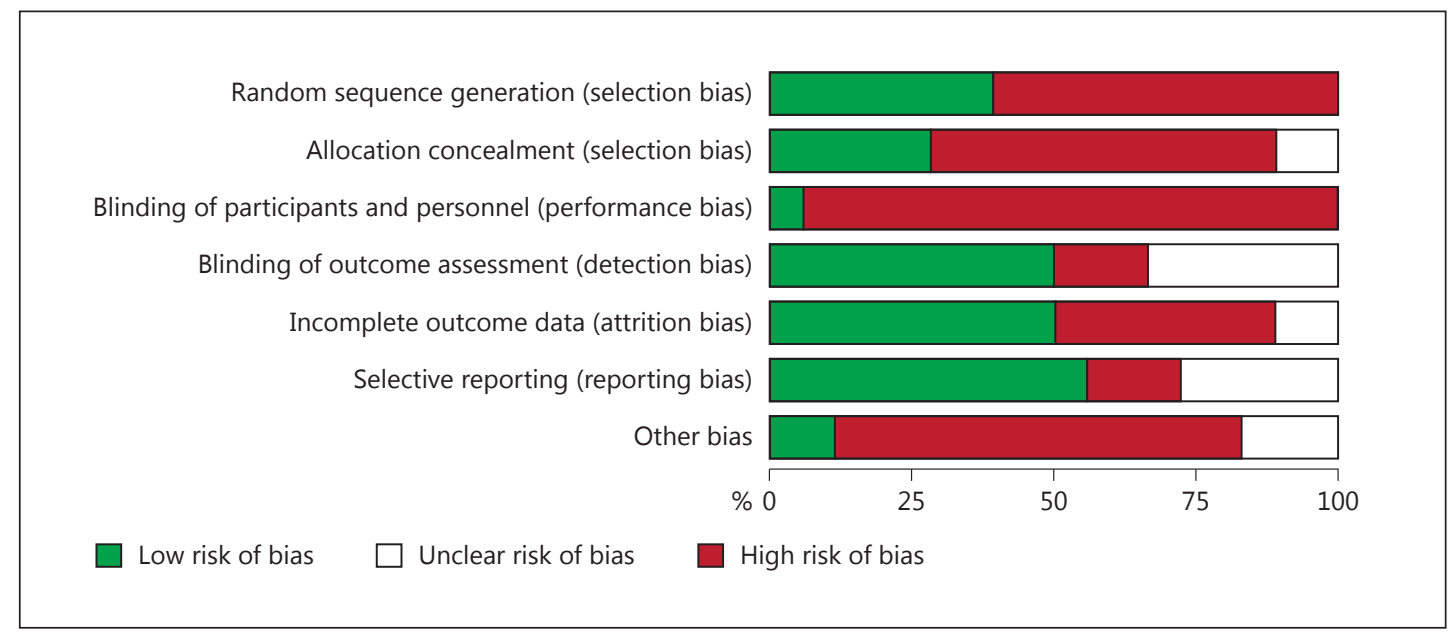

Fig. 2. Risk of bias of studies included in the meta-analysis.

[25-28], and 7 were RCTs (including 2 studies evaluating the benefit of a single session of HT) $[6,14,15,23,29-31]$.

\section{Risk of Bias within Studies}

Quality assessment with the Cochrane Risk of Bias tool is summarized in figure 2. The quality of studies was generally poor to moderate. Most of the studies had no control group, which led to a high risk of selection bias (random sequence generation and allocation concealment). Of 7 RCTs, 4 mentioned allocation concealment [14, 29-31]. Davis et al. [30] and Sterba et al. [24] blinded health providers to avoid performance bias. Blinding of outcome assessment was found to be better as $50 \%$ of studies $[6,14,15,20,23-26,30]$ made efforts in this regard. Seven studies showed a high risk of bias of incomplete outcome data, which mainly resulted from participants' dropping out from the study. Two studies may show a risk of selective reporting $[15,31]$.

\section{Outcomes and Synthesis of Results}

Asymmetry Score

Benda et al. [29] reported improvements in muscle symmetry in children with CP after an 8-min equine-assisted therapy (HT) using the asymmetry score. McGibbon et al. [23] also demonstrated a statistically significant improvement in symmetry during ambulation after a 10-min HT. Only $7 / 8$ (intervention/control) and 25/19 data are available from the patients of Benda and McGibbon's study for the meta-analysis on muscle symmetry, respectively. No other studies reported on this outcome measured by the same tool. The synthesized results are shown in figure 3 . When compared to the control group, although a tendency of reduction of the asymmetry score was observed, it failed to reach statistical significance.

\section{Gross Motor Function Measure}

Cherng et al. [25], Davis et al. [30], Herrero et al. [31], and Kwon et al. [26] reported the effect of HT/THR/AS on the GMFM. Davis et al. and Herrero et al. performed an RCT [30, 31], while Cherng et al. and Kwon et al. utilized a non-RCT design. Cherng et al. and Davis et al. evaluated the effect of a THR, while Herrero et al. evaluated the effect of a HT simulator, and Kwon et al. assessed the effect of a HT program. For the measurements, Cherng et al. eval- 
Wang et al.: The Effect of Riding as an Alternative Treatment for Children with Cerebral

Palsy: A Systematic Review and Meta-Analysis

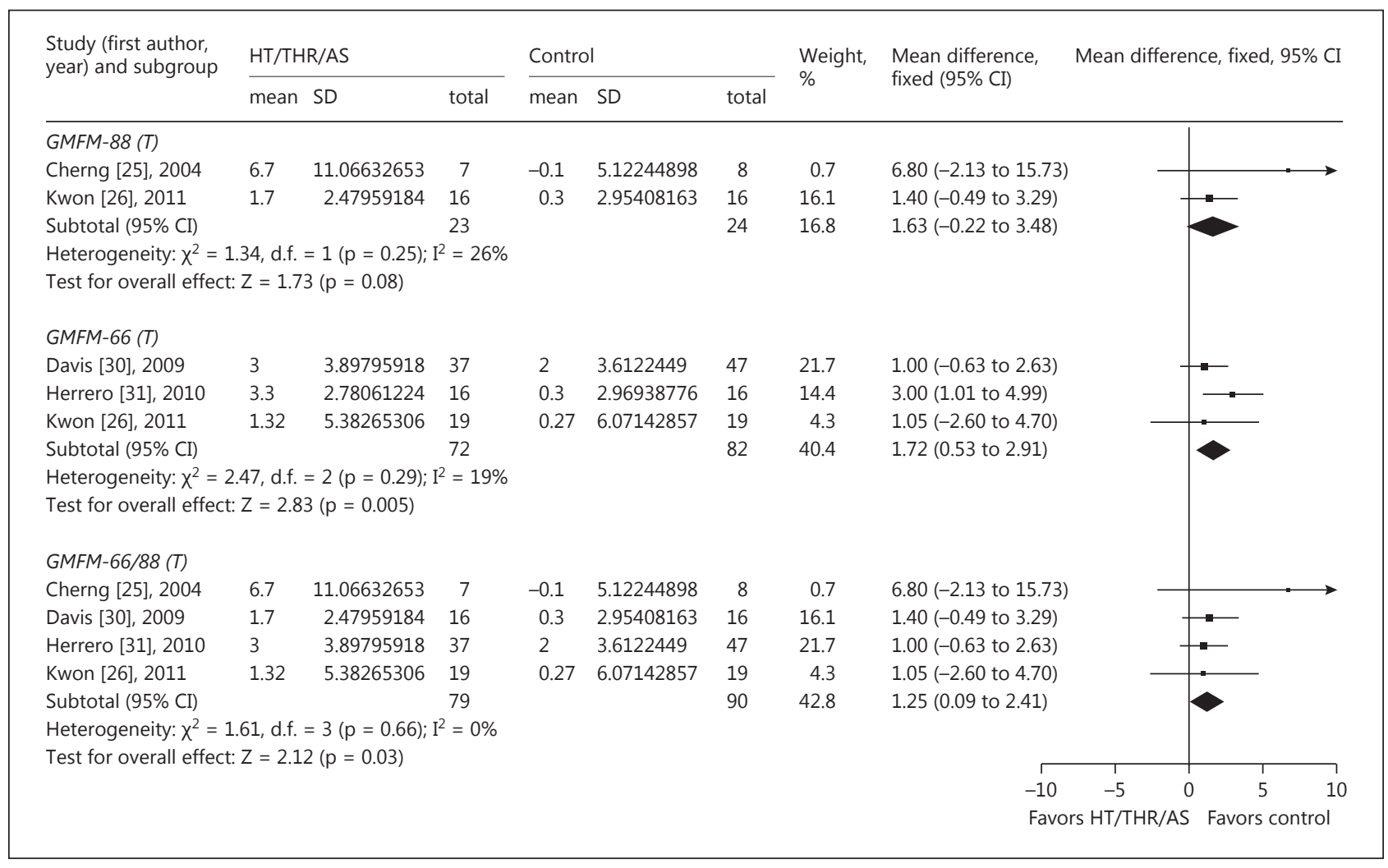

Fig. 3. Effect of HT/THR/AS on the total score of the GMFM.

uated 5 dimensions as well as the total score of the GMFM-88 scale; Kwon et al. evaluated the dimensions D and E, the total score of GMFM-88, and the total score of GMFM-66 (A); Davis et al. evaluated the effect of the total score of GMFM-66, and Herrero et al. assessed the dimension B and the total score of GMFM-66. Cherng et al., Davis et al., Herrero et al., and Kwon et al. included 9/5, 35/36, 19/19, and 16/16 participants (intervention/control), respectively.

Figure 4 depicts the effect of HT/THR/AS on the GMFM total score as compared to a control group. An analysis was performed for GMFM-88 and GMFM-66 separately, as well as combined together. It showed a significant improvement in GMFM-66, and the GMFM-66/88 total score, and a tendency of improvement in the GMFM-88 total score. When expanding the findings to each dimension, for dimensions B, D, and E including more than 2 studies, only dimension E showed a significant improvement (fig. 5). These findings indicate that HT/THR/ AS may improve children's gross motor function through improving the skill of walking, running, and jumping.

\section{Other Outcomes}

A summary of the effects of HT/THR/AS on other outcomes demonstrated with the original studies is presented in table 2. Cherng et al. [25] also investigated the muscle tone of hip adductors with a modified Ashworth Scale, and concluded that there were no significant changes. Herrero et al. [31] used the Sitting Assessment Scale as a support to evaluate the sitting balance and found a significant change (difference between the values in the AS group and control group: -0.59 ; range -0.92 to -0.26 ). Kwon et al. [26] investigated tempo- 
Wang et al.: The Effect of Riding as an Alternative Treatment for Children with Cerebral

\begin{tabular}{|c|c|c|c|c|c|c|c|c|c|c|c|}
\hline \multirow{2}{*}{$\begin{array}{l}\text { Study (first author, } \\
\text { year) and subgroup }\end{array}$} & \multicolumn{3}{|c|}{$\mathrm{HT} / \mathrm{THR} / \mathrm{AS}$} & \multicolumn{3}{|l|}{ Control } & \multirow{2}{*}{$\begin{array}{l}\text { Weight, } \\
\%\end{array}$} & \multirow{2}{*}{$\begin{array}{l}\text { Mean difference, } \\
\text { random }(95 \% \mathrm{CI})\end{array}$} & \multirow{2}{*}{\multicolumn{3}{|c|}{$\begin{array}{l}\text { Mean difference, } \\
\text { random, } 95 \% \mathrm{CI}\end{array}$}} \\
\hline & mean & SD & total & mean & SD & total & & & & & \\
\hline \multicolumn{12}{|l|}{ GMFM-88 (A) } \\
\hline Cherng [25], 2004 & 2 & 1.66326531 & 7 & 0.8 & 0.90306122 & 8 & 44.8 & $1.20(-0.18$ to 2.58$)$ & & $\mathbf{0}$ & \\
\hline Subtotal (95\% CI) & & & 7 & & & 8 & 44.8 & $1.20(-0.18$ to 2.58$)$ & & $T$ & \\
\hline \multicolumn{12}{|c|}{ Heterogeneity: not applicable } \\
\hline \multicolumn{12}{|c|}{ Test for overall effect: $Z=1.70(p=0.09)$} \\
\hline \multicolumn{12}{|l|}{ GMFM-66/88 (B) } \\
\hline Cherng [25], 2004 & 4 & 7.42346939 & 7 & -1.4 & 3.41326531 & 8 & 6.8 & $5.40(-0.59$ to 11.39$)$ & & $\rightarrow$ & \\
\hline Herrero [31], 2010 & 1.27 & 4.87755102 & 19 & 0.11 & 4.85204082 & 19 & 19.8 & $1.16(-1.93$ to 4.25$)$ & & + & \\
\hline Subtotal (95\% CI) & & & 26 & & & 27 & 26.6 & $2.47(-1.37$ to 6.32$)$ & & & \\
\hline \multicolumn{12}{|c|}{$\begin{array}{l}\text { Heterogeneity: } \tau^{2}=3.08, \chi^{2}=1.52, \text { d.f. }=1(p=0.22) ; I^{2}=34 \% \\
\text { Test for overall effect: } Z=1.26(p=0.21)\end{array}$} \\
\hline \multicolumn{12}{|l|}{ GMFM-88 (C) } \\
\hline Cherng [25], 2004 & 5.2 & 12.5 & 7 & -0.6 & 4.69897959 & 8 & 2.7 & $5.80(-4.02$ to 15.62$)$ & & & \\
\hline Subtotal (95\% CI) & & & 7 & & & 8 & 2.7 & $5.80(-4.02$ to 15.62$)$ & & & \\
\hline \multicolumn{12}{|c|}{ Heterogeneity: not applicable } \\
\hline \multicolumn{12}{|c|}{ Test for overall effect: $Z=1.16(p=0.25)$} \\
\hline \multicolumn{12}{|l|}{ GMFM-88 (D) } \\
\hline Cherng [25], 2004 & 10.5 & 21.28571429 & 7 & -1.6 & 13.75 & 8 & 0.8 & $12.10(-6.32$ to 30.52$)$ & & & \\
\hline Kwon [26], 2011 & 0.1 & 3.62244898 & 16 & -0.3 & 7.32142857 & 16 & 13.5 & $0.40(-3.60$ to 4.40$)$ & & & \\
\hline Subtotal (95\% CI) & & & 23 & & & 24 & 14.2 & $2.65(-6.39$ to 11.69$)$ & & & \\
\hline \multicolumn{12}{|c|}{$\begin{array}{l}\text { Heterogeneity: } \tau^{2}=22.18, \chi^{2}=1.48, \text { d.f. }=1(p=0.22) ; I^{2}=32 \% \\
\text { Test for overall effect: } Z=0.57(p=0.57)\end{array}$} \\
\hline \multicolumn{12}{|l|}{ GMFM-88 (E) } \\
\hline Cherng [25], 2004 & 12.3 & 16.96428571 & 7 & 2.4 & 7.2755102 & 8 & 1.4 & 9.90 (-3.64 to 23.44$)$ & & & \\
\hline Kwon [26], 2011 & 7.4 & 6.51530612 & 16 & 1.6 & 7.08673469 & 16 & 10.3 & 5.80 (1.08 to 10.52$)$ & & $\rightarrow$ & \\
\hline Subtotal (95\% CI) & & & 23 & & & 24 & 11.7 & 6.24 (1.79 to 10.70$)$ & & 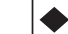 & \\
\hline \multicolumn{12}{|c|}{$\begin{array}{l}\text { Heterogeneity: } \tau^{2}=0.00, \chi^{2}=0.31, \text { d.f. }=1(p=0.58) ; I^{2}=0 \% \\
\text { Test for overall effect: } Z=2.75(p=0.006)\end{array}$} \\
\hline & & $5(p=0.006)$ & & & & & & -50 & -25 & 0 & 25 \\
\hline & & & & & & & & Favo & ors $\mathrm{HT} / \mathrm{TH}$ & AAS $F$ & vors control \\
\hline
\end{tabular}

Fig. 4. Effect of HT/THR/AS on each dimension of the GMFM.

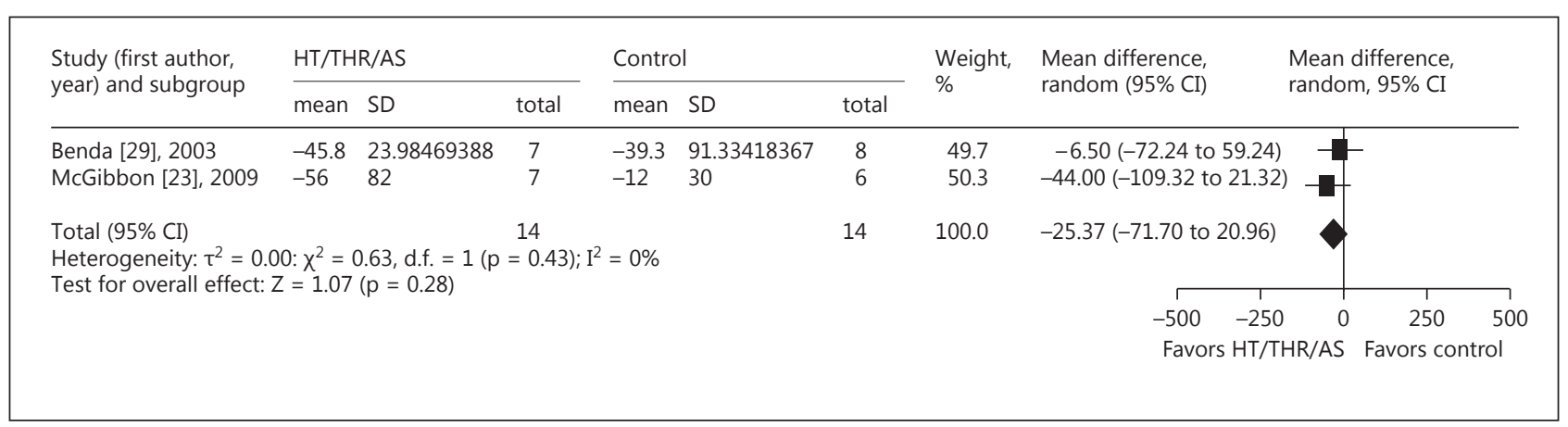

Fig. 5. Effect of HT/THR/AS on the asymmetry score.

rospatial parameters and demonstrated a significantly increased stride length, but no change in cadence; the authors also investigated pelvic and hip kinematics but found no changes. MacKinnon et al. [6] evaluated the quantitative results of a horseback riding program and revealed no statistical benefit of riding for the improvement in the gross motor function and posture (measured by the Bertoti Scale). The only significant result was an improvement in the fine motor function measured by the Peabody Developmental Motor Scale. No meta- 
Wang et al.: The Effect of Riding as an Alternative Treatment for Children with Cerebral

Palsy: A Systematic Review and Meta-Analysis

Table 2. A summary of the effects of HT/THR/AS on other outcomes demonstrated with the original studies

\begin{tabular}{lllll}
\hline Outcome & First author, year & Study design & Measurement & Conclusion \\
\hline Asymmetry score & $\begin{array}{l}\text { Benda [29], 2003; } \\
\text { McGibbon [23], 2009 }\end{array}$ & RCT & 8 min & Improved \\
\hline Sitting assessment scale & Herrero [31], 2010 & Stratified RCT & 10 min & Improved \\
\hline Range of movement & Quint [14], 1998 & Matched RCT & 10 weeks & Improved \\
\hline Ashworth scale & Cherng [25], 2004 & Non-RCT & 4 weeks & NS \\
\hline Pelvic and hip kinematics & Kwon [26], 2011 & Non-RCT & 16 weeks & NS \\
\hline Cadence and stride length & Kwon [26], 2011 & Non-RCT & 8 weeks & Improved \\
\hline AP pelvic & Quint [14], 1998 & Matched RCT & 4 weeks & Improved \\
\hline Sitting posture control (AP, ML) & Silva e Borges [15], 2011 & RCT & 6 weeks & Improved \\
\hline
\end{tabular}

$\mathrm{AP}=$ Anteroposterior; $\mathrm{ML}=$ mediolateral .

analysis was performed for these outcomes since only one study was included for each assessment.

Both Quint and Toomey [14] and Silva e Borges et al. [15] investigated sitting posture control. Quint and Toomey measured a passive pelvic range of movement of anterior and posterior pelvic tilt in sitting using photographs taken from a lateral view [32], while Silva e Borges et al. evaluated the anterior-posterior body oscillations by recording the maximal displacement of the pressure center according to the protocol used by Lacoste et al. [33]. Both studies concluded that riding improved the sitting posture control. No meta-analysis was performed because of the aforementioned heterogeneity in the measurements.

\section{Assessment of Publication Bias across Studies}

Due to a limited number of studies in each meta-analysis, a funnel plot was not drawn. There was an unclear bias in terms of selective publication of a trial.

\section{Discussion}

This is the first study to have systematically evaluated the effect of HT, THR, as well as AS on children with CP. Among 18 studies included for qualitative assessment, 9 studies had a control group and were eligible for quantitative assessment. The quality of the studies varied from poor to moderate, and the sample size in each study differed from around a dozen to dozens of people. The main findings of this study, obtained by means of a meta-analysis, were that HT, THR or AS may improve the symmetry of postural muscle activity, and have a benefit on the total score and the score of the walking, running, and jumping dimension of the gross motor function.

There has been an increasing interest in the potential benefits of horseback riding as a therapeutic intervention since the 1950s; it has been prescribed to improve psychological and physical functions, as primarily reported by Germany researchers. The present review emphasized its physical effects on children with CP. Besides many original studies, Snider 
et al. [34] used a narrative systematic review to evaluate the effect of horseback riding. They drew their conclusions based on an evidence level assessment developed by Sackett et al. [35], and found a level 2a evidence ( $\geq 2$ well-designed RCTs with similar findings of high quality) that a short intervention of HT was effective to treat muscle symmetry and a level 3 evidence that HT improved the gross motor function. Although the methodology they used lacks rigor, their findings were verified by our studies. Our findings on muscle symmetry were consistent with Zadnikar and Kastrin's meta-analysis [36]; however, in their meta-analysis, studies with a control group and those with a repeated measurement design were mixed together and the outcome was the proportion of cases having an effect on postural control or balance, which was not reported as a primary outcome in each of the included study. Tseng et al. [37] conducted a systematic review and meta-analysis on the effect of HT/THR on the asymmetry score and total and dimension scores of the GMFM. They failed to find a benefit of HT on the gross motor function. However, for the synthesis of data, they compared the values before and after HT/THR despite the inclusion of a control group in some of the studies. Using a within-subject before/after design, one could not exclude the possibility that the changes observed in the studies may be due to the nature history of the disease rather than the therapeutic effect, which was the biggest limitation of their study.

Compared with these three systematic reviews/meta-analyses, our study restricted the reports to those with a control group when pooling data together. Sensitivity analysis was also performed with only RCTs. This may be considered as strength of our study. Besides, we avoided combining data when the same outcome was assessed with different measurements, because this may lead to difficulties in the explanation of the result. In addition, our study also included data on the effect of an AS (also named powered saddle or hippotherapy simulator), because of the increasing use of this device, when taken into account the cost and effectiveness inputs as compared to horseback riding therapy on a living horse [13]. This effort may lead to a broader access to the rhythmical, three-dimensional movements either from a horse or a horse simulator.

From the perspective of the supporters of riding therapy, the benefits on physical functions were stated to result from the shape, and rhythmical, three-dimensional movements of a moving horse. The AS simulates these movements and is therefore considered to have the same effects as a living horse [36]. Although in many studies, HT and THR were defined as two quite different modalities, the riders' adjustment of their body to the shifting of the pelvis of a horse/simulator, sustaining their posture during walking/movements, was nevertheless similar in both therapies. Furthermore, adjusting one's position when riding a horse may require more participation of and challenges to the child's body. Because these adjustments involve activity of muscles and joint movements, they may lead to strength of the muscles, balance of the body, and greater range of motion over time.

This study also systematically reviewed outcomes which were evaluated with only one controlled study. These outcomes included gait parameters such as stride length, cadence and walking speed, and pelvic range of movement. Although all primary studies reported positive results, we made sure not to draw a biased conclusion based on evidence from a single controlled study. Instead, a narrative review of these findings was presented in order to offer room for further well-designed studies.

There are some limitations: (1) although 18 studies remained for qualitative synthesis after full-text assessment of eligibility, only 6 of them were qualified for a meta-analysis; (2) the meta-analyses involved several different outcome measures, each of them including only 2-4 studies; (3) a small sample size of the studies and lack of high-quality RCTs, which may introduce uncertainties of the findings. 


\section{Conclusion}

HT/THR/AS seems to improve the total score of the gross motor function viaimprovement of the walking, running, and jumping dimension. However, it is not likely to benefit the symmetry of postural muscle activity. Studies included in this review lack a sufficient number of subjects, and the number of high-quality RCTs is limited, which warrants further evaluation of these modalities using large-scale well-designed RCTs.

\section{Disclosure Statement}

The authors have no potential conflicts of interest to disclose.

\section{References}

1 Fairhurst C: Cerebral palsy: the whys and hows. Arch Dis Child Educ and Pract Ed 2012;97:122-131.

2 Liptak GS: Complementary and alternative therapies for cerebral palsy. Ment Retard Dev Disabil Res Rev 2005;11:156-163.

3 Maurer U: Etiologies of cerebral palsy and classical treatment possibilities. Wien Med Wochenschr 2002;152: 14-18.

4 Biery MJ: Riding and the handicapped. Vet Clin North Am Small Anim Pract 1985;15:345-354.

5 Bertoti DB: Effect of therapeutic horseback riding on posture in children with cerebral palsy. Phys Ther 1988; 68:1505-1512.

6 MacKinnon JR, Noh S, Lariviere J, Macphail A, Allan DE, et al: A study of therapeutic effects of horseback riding for children with cerebral palsy. Phys Occup Ther Pediatr 1995;15:17-34.

7 Haehl V, Giuliani C, Lewis C: Influence of hippotherapy on the kinematics and functional performance of two children with cerebral palsy. Pediatr Phys Ther 1999;11:89-101.

8 Meregillano G: Hippotherapy. Phys Med Rehabil Clin N Am 2004;15:843-854, vii.

9 Wingate L: Feasibility of horseback riding as a therapeutic and integrative program for handicapped children. Phys Ther 1982;62:184-186.

10 Hamill D, Washington KA, White OR: The effect of hippotherapy on postural control in sitting for children with cerebral palsy. Phys Occup Ther Pediatr 2007;27:23-42.

11 Debuse D, Gibb C, Chandler C: Effects of hippotherapy on people with cerebral palsy from the users' perspective: a qualitative study. Physiother Theory Pract 2009;25:174-192.

12 Winchester P, Kendall K, Peters H, Sears N, Winkley T: The effect of therapeutic horseback riding on gross motor function and gait speed in children who are developmentally delayed. Phys Occup Ther Pediatr 2002; 22:37-50.

13 Moster H: The electric saddle horse. An aid in the therapy of infantile cerebral paresis (in German). Behinderte Kind 1975;12:19-20.

14 Quint C, Toomey M: Powered saddle and pelvic mobility. An investigation into the effects on pelvic mobility of children with cerebral palsy of a powered saddle which imitates the movements of a walking horse. Physiotherapy 1998;84:376-384.

15 Silva e Borges MB, Werneck MJ, da Silva Mde L, Gandolfi L, Pratesi R: Therapeutic effects of a horse riding simulator in children with cerebral palsy. Arq Neuropsiquiatr 2011;69:799-804.

16 Moher D, Cook DJ, Eastwood S, Olkin I, Rennie D, et al: Improving the quality of reports of meta-analyses of randomised controlled trials: the QUOROM statement. Quality of Reporting of Meta-analyses. Lancet 1999; 354:1896-1900.

17 Moher D, Liberati A, Tetzlaff J, Altman DG: Preferred reporting items for systematic reviews and meta-analyses: the PRISMA statement. PLoS Med 2009;6:e1000097.

18 Cram JR, Kasman GS, Holtz J: Introduction to Surface Electromyography. Gaithersburg, Aspen Publishers, 1998.

19 Russell DJ, Rosenbaum PI, Avery LM, Lane M: Gross Motor Function Measure (GMFM-66 and GMFM-88) User's Manual. Clinics in Developmental Medicine No 159. London, Mac Keith Press, 2002.

20 Casady RL, Nichols-Larsen DS: The effect of hippotherapy on ten children with cerebral palsy. Pediatr Phys Ther 2004;16:165-172.

21 McGibbon NH, Andrade CK, Widener G, Cintas HL: Effect of an equine-movement therapy program on gait, energy expenditure, and motor function in children with spastic cerebral palsy: a pilot study. Dev Med Child Neurol 1998;40:754-762.

22 McGee MC, Reese NB: Immediate effects of a hippotherapy session on gait parameters in children with spastic cerebral palsy. Pediatr Phys Ther 2009;21:212-218. 
23 McGibbon NH, Benda W, Duncan BR, Silkwood-Sherer D: Immediate and long-term effects of hippotherapy on symmetry of adductor muscle activity and functional ability in children with spastic cerebral palsy. Arch Phys Med Rehabil 2009;90:966-974.

24 Sterba JA, Rogers BT, France AP, Vokes DA: Horseback riding in children with cerebral palsy: effect on gross motor function. Dev Med Child Neurol 2002;44:301-308.

25 Cherng RJ, Liao HF, Leung HWC, Hwang AW: The effectiveness of therapeutic horseback riding in children with spastic cerebral palsy. Adapt Phys Activ Q 2004;21:103-121.

26 Kwon JY, Chang HJ, Lee JY, Ha Y, Lee PK, et al: Effects of hippotherapy on gait parameters in children with bilateral spastic cerebral palsy. Arch Phys Med Rehabil 2011;92:774-779.

27 Shurtleff TL, Standeven JW, Engsberg JR: Changes in dynamic trunk/head stability and functional reach after hippotherapy. Arch Phys Med Rehabil 2009;90:1185-1195.

28 Shurtleff TL, Engsberg JR: Changes in trunk and head stability in children with cerebral palsy after hippotherapy: a pilot study. Phys Occup Ther Pediatr 2010;30:150-163.

29 Benda W, McGibbon NH, Grant KL: Improvements in muscle symmetry in children with cerebral palsy after equine-assisted therapy (hippotherapy). J Altern Complement Med 2003;9:817-825.

30 Davis E, Davies B, Wolfe R, Raadsveld R, Heine B, et al: A randomized controlled trial of the impact of therapeutic horse riding on the quality of life, health, and function of children with cerebral palsy. Dev Med Child Neurol 2009;51:111-119.

31 Herrero P, Asensio A, Garcia E, Marco A, Olivan B, et al: Study of the therapeutic effects of an advanced hippotherapy simulator in children with cerebral palsy: a randomised controlled trial. BMC Musculoskelet Disord 2010;11:71.

32 Myhr U, von Wendt L: Improvement of functional sitting position for children with cerebral palsy. Dev Med Child Neurol 1991;33:246-256.

33 Lacoste M, Therrien M, Cote JN, Shrier I, Labelle H, et al: Assessment of seated postural control in children: comparison of a force platform versus a pressure mapping system. Arch Phys Med Rehabil 2006;87:16231629.

34 Snider L, Korner-Bitensky N, Kammann C, Warner S, Saleh M: Horseback riding as therapy for children with cerebral palsy: is there evidence of its effectiveness? Phys Occup Ther Pediatr 2007;27:5-23.

35 Sackett Dl, Richardson WS, Rosenberg W, Haynes RB: Evidence-Based Medicine: How to Practice and Teach EBM, ed 2. New York, Churchill Livingstone, 2000.

36 Zadnikar M, Kastrin A: Effects of hippotherapy and therapeutic horseback riding on postural control or balance in children with cerebral palsy: a meta-analysis. Dev Med Child Neurol 2011;53:684-691.

37 Tseng SH, Chen HC, Tam KW: Systematic review and meta-analysis of the effect of equine assisted activities and therapies on gross motor outcome in children with cerebral palsy. Disabil Rehabil 2013;35:89-99. 